\title{
MATLAB User Interface for Simulation of Silicon Germanium Solar Cell
}

\author{
Ashish Kumar Singh, Jahnvi Tiwari, Ashish Yadav, and Rakesh Kumar Jha \\ School of Electronics and Communication, Shri Mata Vaishno Devi University, Katra 182320, India \\ Correspondence should be addressed to Ashish Kumar Singh; ashishresonance@rediffmail.com
}

Received 22 June 2015; Revised 24 July 2015; Accepted 5 August 2015

Academic Editor: Rodrigo Martins

Copyright (C) 2015 Ashish Kumar Singh et al. This is an open access article distributed under the Creative Commons Attribution License, which permits unrestricted use, distribution, and reproduction in any medium, provided the original work is properly cited.

\begin{abstract}
Nuclear fusion reaction on the sun is the largest source of energy. In this paper, qualitative investigation of the numerical model of silicon germanium heterojunction solar cell is performed using MATLAB graphical user interface. The heterostructure is designed as $\mathrm{Si}_{1-x} \mathrm{Ge}_{x}$ for speculative determination of appropriate germanium mole fraction to get the maximized thin-film solar cell efficiency $(\dot{\eta})$. Other characteristics such as absorption coefficient $(\alpha)$, energy band gap $\left(E_{g_{\mathrm{SiGe}}}\right)$, reflectivity $(r)$, open circuit voltage $\left(V_{\mathrm{oc}}\right)$, and generation rate $(G(\lambda, x))$ are also considered. This user interface will reduce the complexity of solving differential equation for the analysis of silicon germanium heterojunction cell.
\end{abstract}

\section{Introduction}

Due to the constant increase in pressure on the nonrenewable energy sources, renewable energy sources are gaining popularity. Solar cell is an efficient type of renewable energy source. As compared to $\mathrm{Si}, \mathrm{Ge}$ has steeper absorption edge and generally optical absorption coefficient of $\mathrm{Ge}$ is higher than that of Si. Silicon junction is stacked on top of a germanium junction for the enhancement of efficiency from a single junction $\mathrm{Si}$ solar cell [1]. The SiGe absorption behavior results in current gain, but at same time energy band gap of SiGe decreases. Various analyses on thin-film SiGe solar cells are carried to improve the characteristics and efficiency [2].

Heterojunction solar cells have a great advantage of achieving high electrical voltage [3] because material with large band has low minority charge concentration which leads to minimum recombination at the interface. For selection of better solar cell, semiconductor should be chosen on the basis of spectrum absorption [4]. Semiconductors like silicon and germanium have indirect band gap as shown in Figure 1 and it is used as an absorber in solar cell [5]. If we introduce Ge content in SiGe alloy its indirect band gap decreases. The main function of any indirect band gap semiconductor is trapping light; this can be enhanced by optimum texturing. Indirect band gap semiconductor also has high recombination lifetime and large diffusion length $[6,7]$.

Section 2 features the user interface. Section 3 includes the work of software interface; the structure of SiGe solar cell is modelled in Section 4. Section 5 focuses on the properties of SiGe alloy. Simulation results are presented in Section 6 with the simulated data.

\section{User Interface Features}

The purpose of this user interface is to develop a general purpose solar device simulator that is functional and modular in nature to allow flexibility during programming and provide sufficient scope for future developments. In addition, the program's main goal is to provide a tool that can supplement solar cell modeling, device physics and to construct basic cell equations using MATLAB tools. MATLAB's capability and inherent nature of handling matrices and matrix operations make it an optimum software for numerical analysis algorithms. A device modeling program is developed using basic MATLAB tools necessary to understand the operation of the program. The program solution will be used to examine device parameters such as carrier statistics, device potential, and internal electric fields. The device solution is compared to the analytical approximations in order to further 


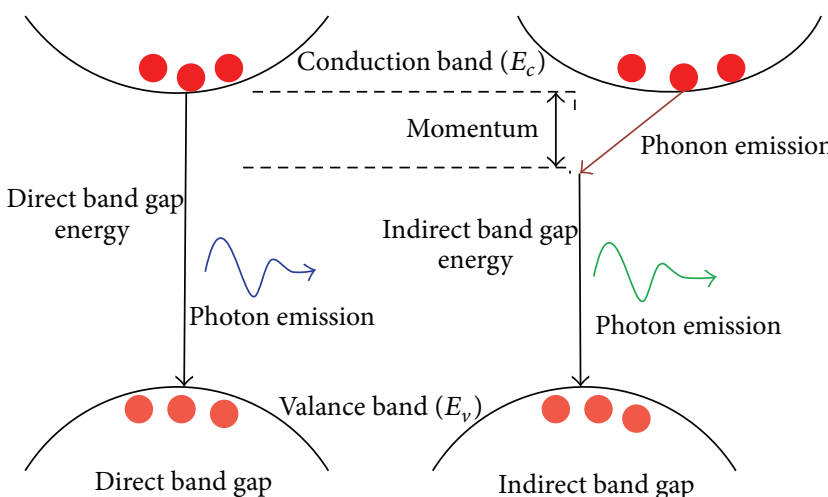

FIGURE 1: Direct and indirect band gap.

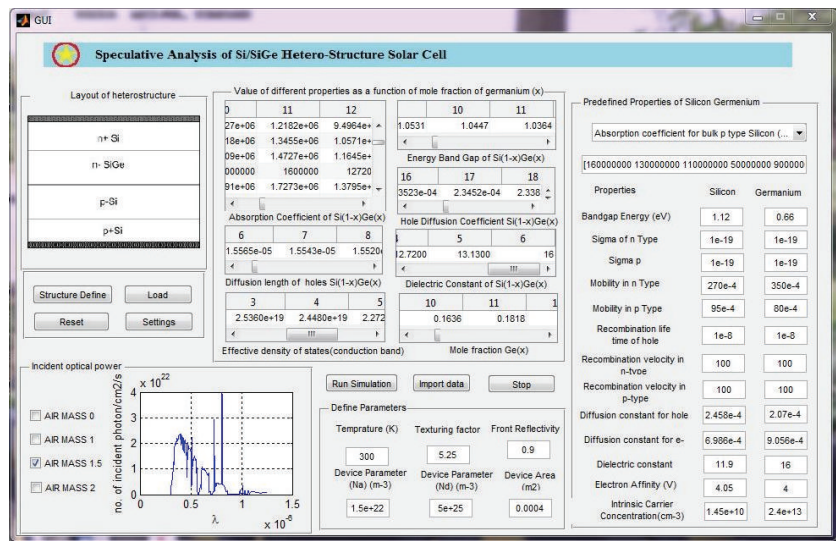

Figure 2: MATLAB GUI.

strengthen the understanding between theory and exact numerical solutions and how those solutions are obtained. In this software, silicon germanium solar cell analysis can be performed easily. Cell structure dimension is used with predefined parameters and electrical properties to solve the complex equation internally to provide best and instant result. Properties of silicon and germanium are prestored in GUI.

\section{Graphical User Interface Working}

Figure 2 shows the main window of this program. Initially, incident optical power is selected and different parameters like temperature, texturing factor, front reflectivity, device area, and device parameters are defined. In this program, properties of silicon and germanium are predefined, it can also be changed (increase digit after decimal), as per requirement for exact result, with the help of "Settings" button. Reset button is used to reconfigure the whole window except the predefined parameters. Button labeled as "Structure Define" is used for designing the layout of heterojunction $\mathrm{Si} / \mathrm{SiGe}$ solar plate layer. Structure design is linked to new graphical user interface where it is loaded for further configuration settings of the model. Here, parameters like concentration, thickness of $\mathrm{Si}, \mathrm{SiGe}$, and lifetime of minority carrier $\left(\tau_{p}\right)$, along with mole fraction range, are required.

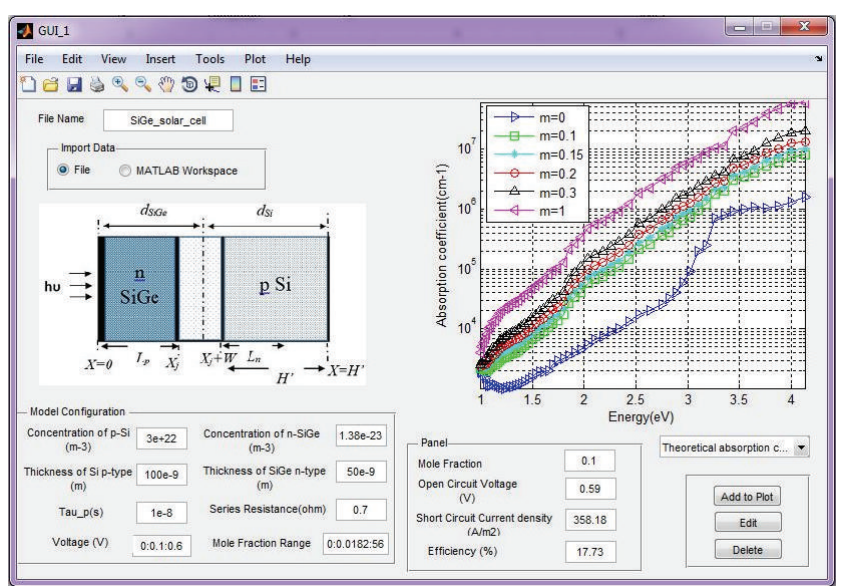

FIGURE 3: Structure define GUI.

For simulation purpose, enter the name of file and from the pop menu select the graph which is to be plotted. Simulate the result, which can be imported from MATLAB workspace or from a different folder. Figure 3 shows the simulation of absorption coefficient versus photon energy. It also simulates the value of the exact mole fraction, open circuit voltage, and short circuit current density at which efficiency is the maximum.

\section{Cell Structure Properties}

Any new method or other characterization methods with advanced numerical model can be simulated by changing the values and range of parameters. Developed numerical model [9]: thin layer of highly doped $\mathrm{n}$-Si is constructed with a dimension of $5 \times 10^{-9} \mathrm{~m}$ as a capping layer to increase luminescence efficiency. Alloy of silicon germanium is used in this layer and thickness $d_{\mathrm{SiGe}}$ is $50 \times 10^{-9} \mathrm{~m}$. Final layer is p-type doped silicon layer with thickness $d_{\mathrm{Si}}=100 \times 10^{-9} \mathrm{~m}$. The model is designed in such a way that numerical cell is represented in the form $\mathrm{Si}_{1-x} \mathrm{Ge}_{x}$, where $x$ is the mole fraction of germanium which varies from $x=0$, that is, pure silicon, until $x=1$, that is, pure germanium, as shown in Figure 4 . The surface recombination velocities $\left(S_{P}\right)$ are $10^{2} \mathrm{~m} / \mathrm{s}$ at the front side and $\infty$ for the backside.

\section{Properties of SiGe Alloy}

The software calculates different properties corresponding to the mole fraction range (entered in structure define GUI_1). To compute different properties of alloy of silicon germanium, we need to analyze both semiconductors individually. To combine the effect of both semiconductors, Vegard's law is used, and this can be represented as [9]

$$
P_{\mathrm{SiGe}}=P_{\mathrm{Si}}(1-X)+P_{\mathrm{Ge}}(X),
$$

where $P_{\mathrm{SiGe}}$ is the property of SiGe alloy, $P_{\mathrm{Si}}$ is the property of silicon, $P_{\mathrm{Ge}}$ is the property of germanium, and $X$ is the mole fraction of $\mathrm{Ge}$. 


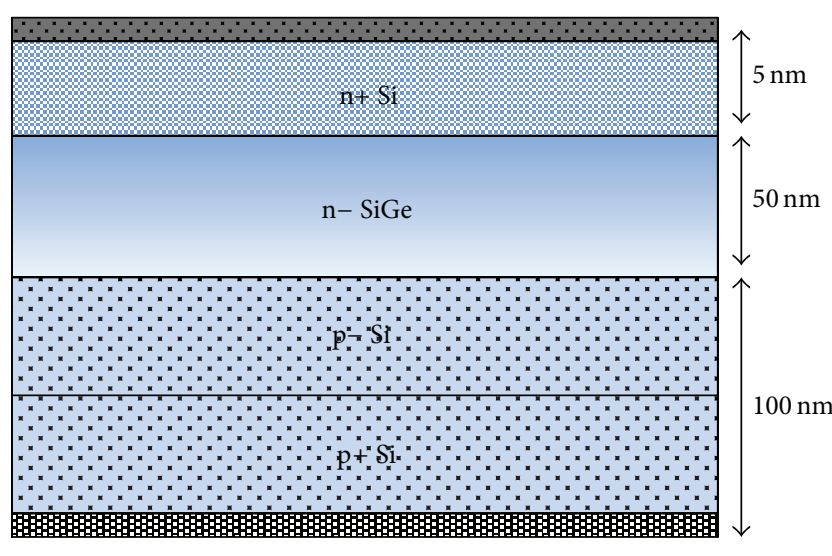

Figure 4: Schematic structure of Si/SiGe heterojunction solar cell.

Dielectric Constant $\left(\varepsilon_{r}\right)$. The permittivity or relative dielectric constant of material is as follows:

$$
\varepsilon_{r_{\text {siGe }}}=11.9+4.1 X \text {. }
$$

Diffusion Length of Minority Holes $\left(L_{p}\right)$. It is expressed as an average distance a carrier can move from the point of generation to recombination. Parameters play an important role in deciding the suitability of the material to be used as solar cell [10]

$$
L_{p}=\sqrt{D_{p} \tau_{p}}
$$

where $\tau_{p}$ is the lifetime of minority holes in $\mathrm{n}$-SiGe.

Energy Band Gap $\left(E_{g}\right)$. It is the minimum amount of energy required for an electron to break free of its bound state. Due to the different thickness of $\mathrm{Si}$ and Ge alloys, the stacked layers are formed which relates to different energy thresholds, absorbing a different band of the solar spectrum over a wide range from silicon $(1.12 \mathrm{eV})$ to germanium $(0.66 \mathrm{eV})$. For type-I heterostructure, we use the relation

$$
\Delta E_{g}=\Delta E_{v}+\Delta E_{c} .
$$

Effective Density of States in Valence Band $\left(N_{v}\right)$. Semiconductor's conductivity can be given by the relation

$$
(\sigma)=q\left(\mu_{n} n+\mu_{p} p\right),
$$

where $\mu_{n}$ is electron mobility, $\mu_{p}$ is hole mobility, $n$ and $p$ are electron and hole concentration, respectively. According to Maxwell-Boltzmann approximation, $p$ depends on $N_{v}$ (effective density of states in valence band).

Effective Density of States in Conduction Band $\left(N_{c}\right)$. According to Maxwell-Boltzmann approximation, $n$ depends on $N_{c}$ (effective density of states in conduction band)

$$
n_{i_{\text {SiGe }}}^{2}=N_{c_{\text {SiGe }}} N_{v_{\text {SiGe }}} e^{\left[-E_{g} / K T\right]},
$$

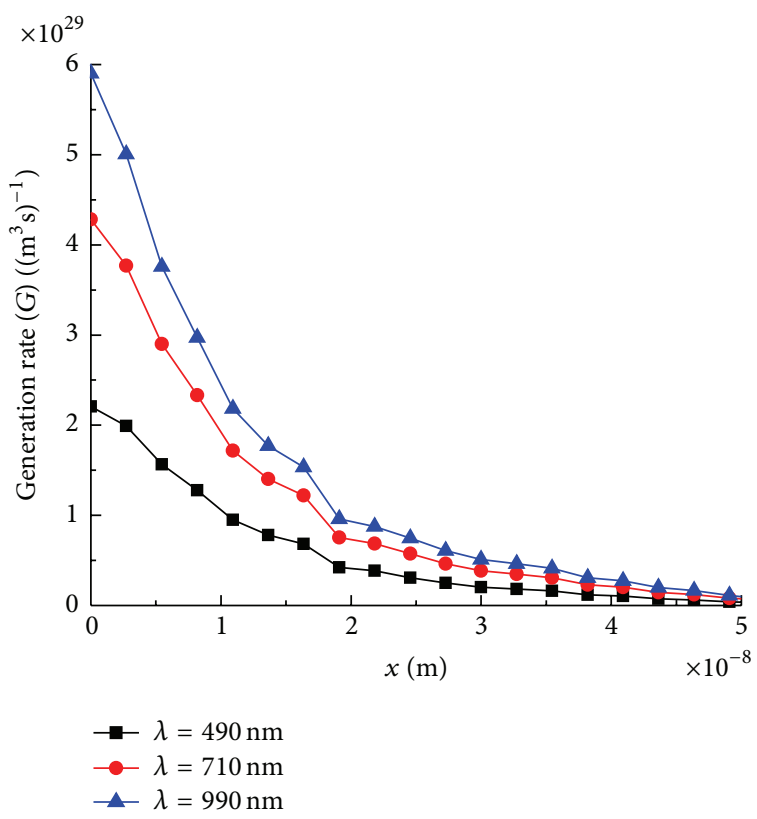

Figure 5: Generation rate at different wavelength.

where $n_{i_{\text {SiGe }}}$ is the intrinsic carrier concentration, $E_{g}$ is the energy band gap, and $x$ is the Ge mole fraction [11]. The $n_{i_{\text {siGe }}}, N_{v_{\text {SiGe }}}$, and $N_{c_{\text {SiGe }}}$ values for different $x$ values in $\mathrm{Si}_{1-x} \mathrm{Ge}_{x}$ heterolayers are in $[9]$.

\section{Simulation Result and Discussion}

The absorption coefficients for $n$ type $\mathrm{Si}$ and Ge and most of the parameters are taken from [12,13]. The numerical value of the simulated properties of the alloy of $\mathrm{SiGe}$ is explained in Section 3. From Figure 2, it can be observed that important parameter at specified mole fraction is calculated and displayed in different tables as shown in Table 1. Results are simulated using this user interface and data is exported to OriginPro software for plotting. Some important results are shown.

6.1. Generation Rate. Absorption of photon in material leads to the number of electrons generated at each point. After reflection, the intensity of light to be absorbed depends on the material thickness and absorption as shown in the following equation:

$$
G(\lambda, x)=\alpha(\lambda) F(\lambda)[1-R(\lambda)] e^{-\alpha(\lambda) x},
$$

where $\alpha(\lambda)$ is the absorption coefficient of SiGe, $R(\lambda)$ is the reflectivity of silicon, $F(\lambda)$ is the number of incident photons per area per second, and $x$ is the depth of layer of SiGe layer. Incident light is the combination of different wavelengths; therefore, generation rate corresponding to different wavelengths is shown in Figure 5.

To compute cumulative generation rate at different wavelengths, the sum of generation rate is calculated and used. From Figure 5, it is observed that, for the increase in wavelength, we get new shifted curve. Shifting is a cumulative 
TABLE 1: Value of different properties as a function of mole fraction of germanium $(x)$.

\begin{tabular}{lccccccc}
\hline Properties of $\mathrm{Si}_{1-x} \mathrm{Ge}_{x}$ & $\mathrm{Si}$ & $\mathrm{Si}_{0.9} \mathrm{Ge}_{0.1}$ & $\mathrm{Si}_{0.85} \mathrm{Ge}_{0.15}$ & $\mathrm{Si}_{0.8} \mathrm{Ge}_{0.2}$ & $\mathrm{Si}_{0.75} \mathrm{Ge}_{0.25}$ & $\mathrm{Si}_{0.7} \mathrm{Ge}_{0.3}$ & $\mathrm{Ge}$ \\
\hline$\varepsilon_{r}$ & 11.9 & 12.31 & 12.51 & 12.72 & 12.92 & 13.13 & 16 \\
$E_{g}(\mathrm{ev})$ & 1.12 & 1.074 & 1.051 & 1.028 & 1.005 & 0.982 \\
$D_{p}\left(\mathrm{~m}^{2} / \mathrm{s}\right)$ & $2.458 \times 10^{-4}$ & $2.419 \times 10^{-4}$ & $2.399 \times 10^{-4}$ & $2.38 \times 10^{-4}$ & $2.361 \times 10^{-4}$ & $2.341 \times 10^{-4}$ & $2.07 \times 10^{-4}$ \\
$D_{n}\left(\mathrm{~m}^{2} / \mathrm{s}\right)$ & $6.986 \times 10^{-4}$ & $7.193 \times 10^{-4}$ & $7.3 \times 10^{-4}$ & $7.40 \times 10^{-4}$ & $7.50 \times 10^{-4}$ & $7.60 \times 10^{-4}$ & $9.056 \times 10^{-4}$ \\
$L_{p}(\mathrm{~m})$ & $1.567 \times 10^{-5}$ & $1.554 \times 10^{-5}$ & $1.549 \times 10^{-5}$ & $1.542 \times 10^{-5}$ & $1.536 \times 10^{-4}$ & $1.529 \times 10^{-5}$ & $1.438 \times 10^{-5}$ \\
$N_{v}\left(\mathrm{~cm}^{-3}\right)$ & $1.04 \times 10^{19}$ & $9.96 \times 10^{18}$ & $9.74 \times 10^{18}$ & $9.52 \times 10^{18}$ & $9.3 \times 10^{18}$ & $9.08 \times 10^{18}$ & $6 \times 10^{18}$ \\
$N_{c}\left(\mathrm{~cm}^{-3}\right)$ & $2.8 \times 10^{19}$ & $2.62 \times 10^{19}$ & $2.53 \times 10^{19}$ & $2.44 \times 10^{19}$ & $2.36 \times 10^{19}$ & $2.27 \times 10^{19}$ & $1.04 \times 10^{19}$ \\
$n_{i}\left(\mathrm{~cm}^{-3}\right)$ & $1.45 \times 10^{10}$ & $2.413 \times 10^{12}$ & $3.612 \times 10^{12}$ & $4.81 \times 10^{12}$ & $6.01 \times 10^{12}$ & $7.21 \times 10^{12}$ & $2.4 \times 10^{13}$ \\
\hline
\end{tabular}

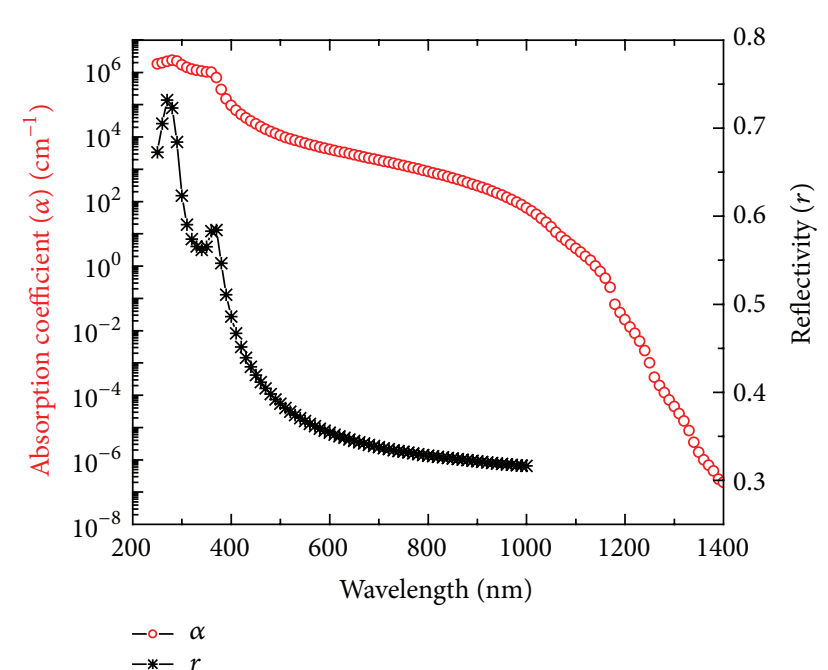

FIGURE 6: Silicon absorption coefficient and reflectivity with respect to wavelength.

effect of parameter such as absorption coefficients, reflectivity, and number of incident photons. When wavelength is increased, it leads to a decrease in both absorption coefficients and fraction of photon reflected as shown in Figure 6. Including all these factors along with the number of photons generated, the net effect increases the generation rate.

6.2. Absorption Coefficient versus Photon Energy of $\mathrm{Si}_{1-x} G e_{x}$. Absorption coefficient is a major parameter to decide at what material depth the light of particular wavelength can penetrate before it is absorbed. This coefficient depends on the material and the wavelength. In a semiconductor, having larger material absorption coefficient, the photons get more rapidly absorbed as well as the results in electron excitation in the conduction band. Therefore, selection of material for better solar cell is done with speculative analysis of the different characteristics of solar cell, and absorption coefficient is one of it. Therefore, the curve of absorption coefficient as a function of germanium mole fraction is plotted in Figure 7. Incident optical power under AM 1.5 is used for the simulation of $\alpha_{\mathrm{Si}_{1-x} \mathrm{Ge}_{x}}$. From Figure 7, it is observed that the absorption coefficient of $\mathrm{Si}$ is lower than Ge. Therefore, for photovoltaic material, crystalline Ge is better than crystalline $\mathrm{Si}$ because the optical absorption

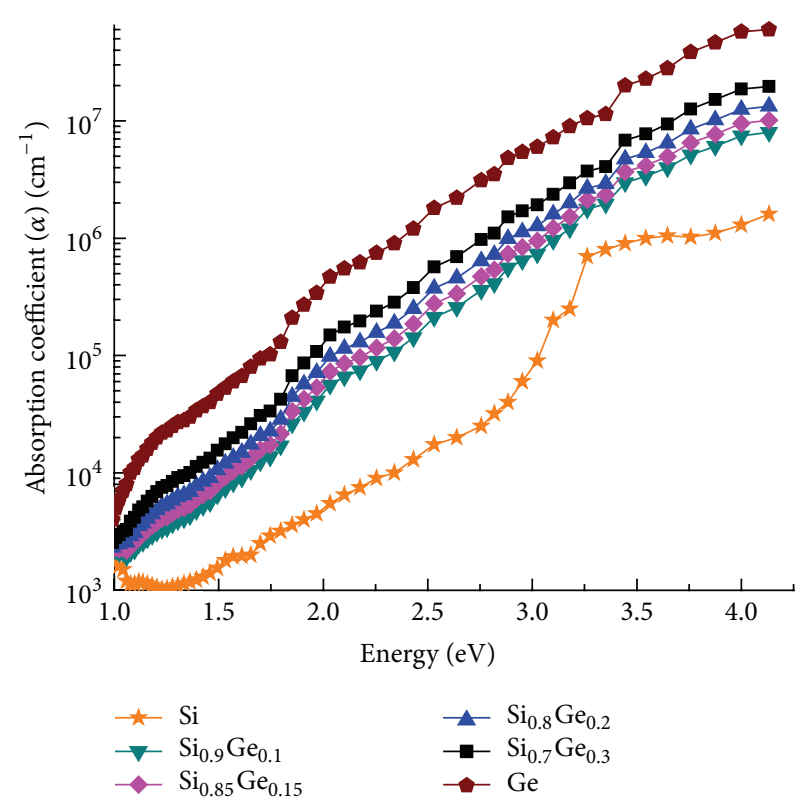

FIgURE 7: Theoretical absorption coefficient with photon energy of $\mathrm{Si}_{1-x} \mathrm{Ge}_{x}$.

of germanium has a wider spectral overlap with the solar irradiance spectrum (Ge and Si cover 300 to $1600 \mathrm{~nm}$ and 300 to $1060 \mathrm{~nm}$ wavelength range, resp.) [1].

6.3. Current Density of $S i_{1-x} G e_{x}$. Software compiles and produces current voltage characteristics curve with the help of predefined parameters, user defined parameters, constants, and silicon germanium properties, as shown in Figure 8. For the calculation of the total generated photocurrent, the program calculates the conduction current density due to holes and diffusion current density due to electrons and drift current density with the help of the equation in [9]. Current density at different Ge mole fraction is plotted as a function of voltage. It can be observed that when mole fraction is " 0.3 ," the current density is the least, while if we take the value of the current density at $\operatorname{Ge}(x)=0.25$, it is increased. This behavior keeps on continuing, but certainly at mole fraction " 0.15 ," the current density becomes the maximum. Therefore, on the basis of the theoretical observation, mole fraction between " 0.1 " and " 0.15 " for different characteristics is analyzed. 
TABLE 2: Parameters obtained from simulator.

\begin{tabular}{lccccccccc}
\hline $\begin{array}{l}\text { Illumination } \\
\text { spectrum }\end{array}$ & $R$ & $\begin{array}{c}\text { Mole } \\
\text { fraction }\end{array}$ & $\begin{array}{c}S_{P} \\
(\mathrm{~m} / \mathrm{s})\end{array}$ & $\begin{array}{c}\tau_{p} \\
(\mathrm{~s})\end{array}$ & $\begin{array}{c}N_{A} \\
\left(\mathrm{~m}^{-3}\right)\end{array}$ & $\begin{array}{c}N_{D} \\
\left(\mathrm{~m}^{-3}\right)\end{array}$ & $\begin{array}{c}V_{\text {oc }} \\
(\mathrm{V})\end{array}$ & $\begin{array}{c}J_{\text {sc }} \\
\left(\mathrm{A} / \mathrm{m}^{2}\right)\end{array}$ & $\begin{array}{c}\text { Efficiency } \\
(\%)\end{array}$ \\
\hline AM 1.5 & 0.9 & $0(\mathrm{Si})$ & 100 & $10^{-8}$ & $1.5 \times 10^{22}$ & $5 \times 10^{25}$ & 0.68 & 78.94 & 4.67 \\
AM 1.5 & 0.9 & $0.1\left(\mathrm{Si}_{0.9} \mathrm{Ge}_{0.1}\right)$ & 100 & $10^{-8}$ & $1.5 \times 10^{22}$ & $5 \times 10^{25}$ & 0.59 & 358.18 & 17.73 \\
AM 1.5 & 0.9 & $0.15\left(\mathrm{Si}_{0.85} \mathrm{Ge}_{0.15}\right)$ & 100 & $10^{-8}$ & $1.5 \times 10^{22}$ & $5 \times 10^{25}$ & 0.56 & 382.5 & 17.47 \\
\hline
\end{tabular}

TABLE 3: Comparison of efficiency of different model at the same mole fraction.

\begin{tabular}{lcccc}
\hline Different model & $\begin{array}{c}\text { Mole } \\
\text { fraction }\end{array}$ & $\begin{array}{c}J_{\text {sc }} \\
\left(\mathrm{A} / \mathrm{m}^{2}\right)\end{array}$ & $\begin{array}{c}V_{\text {oc }} \\
(\mathrm{V})\end{array}$ & $\begin{array}{c}\text { Efficiency } \\
(\%)\end{array}$ \\
\hline The proposed model & 0.1 & 358.18 & 0.59 & 17.73 \\
Said et al. [8] & 0.1 & 183 & 0.55 & 7.5 \\
\hline
\end{tabular}

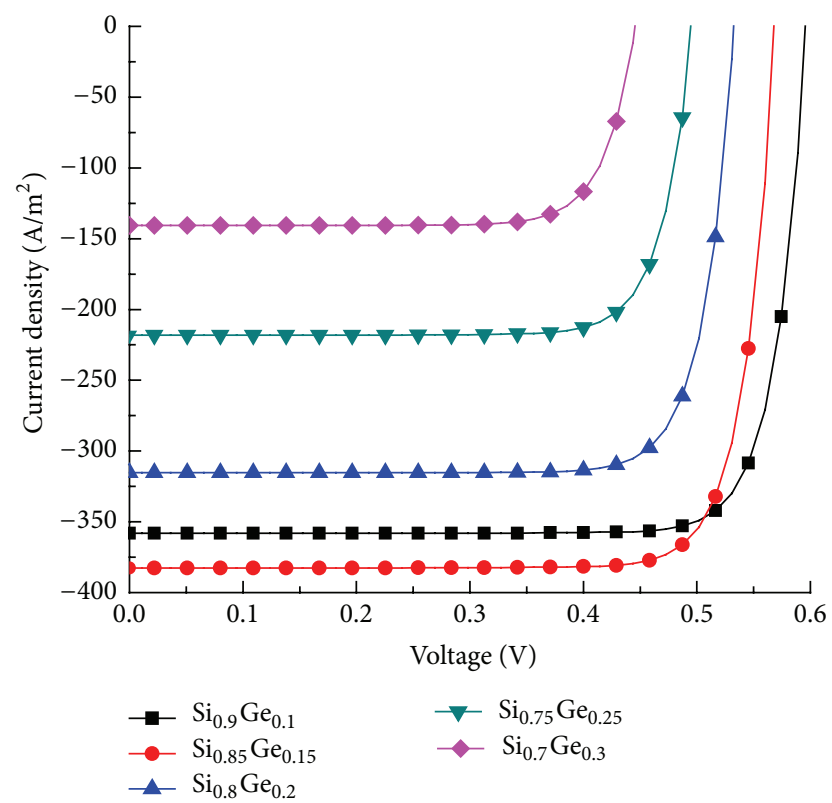

FIGURE 8: Current density voltage curve of $\mathrm{Si}_{1-x} \mathrm{Ge}_{x}$.

6.4. Open Circuit Voltage and Short Circuit Current of $S i_{1-x} G e_{x}$. Open circuit voltage is the maximum voltage of solar plate and it occurs when the current is zero. It corresponds to the amount of forward biased solar cell due to the bias of cell junction with the light generated current [10]. It can be expressed as

$$
V_{\mathrm{oc}}=\frac{n k T}{q} \log _{e}\left(\frac{I_{L}}{I_{s}}+1\right),
$$

where $I_{s}$ is dark saturation current, $I_{L}$ is light generated current, $k$ is Boltzmann's constant, $T$ is temperature in kelvin, $n$ is ideality factor, and $q$ is charge of an electron. From (8), it is concluded that open circuit voltage depends on $I_{L}=I_{\mathrm{sc}}$ (short circuit current) and $I_{s}$, but actually the variation of $I_{\mathrm{sc}}$ is small. Therefore, it depends on the saturation current which may vary up to a significant margin. When mole fraction is increased, energy band gap of $\mathrm{SiGe}$ slopes down, which results in the increase in saturation current $\left(I_{s}\right)$, as explained

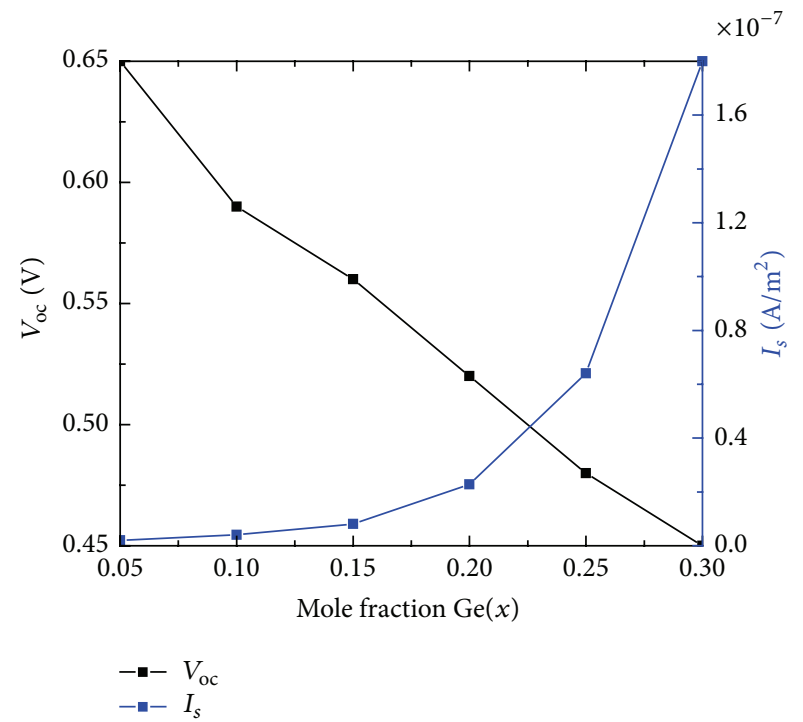

FIGURE 9: Open circuit voltage and saturation current as a function of mole fraction of Ge.

in [9] and as shown in Figure 9. Therefore, the combined effect of saturation current and short circuit current results in the decrease in the value of $V_{\mathrm{oc}}$ when mole fraction is increased. Value of $V_{\text {oc }}, J_{\text {sc }}$ for better and efficient solar cell model is calculated and is displayed in the output panel: germanium mole fraction is "0.1," where open circuit voltage is " $0.59 \mathrm{~V}$ " and short circuit current density is $358.18 \mathrm{~A} / \mathrm{m}^{2}$, producing the maximum efficiency of 17.73 (\%). Efficiency was calculated assuming $1000 \mathrm{~W} / \mathrm{m}^{2}$ as the input power.

The maximum theoretical efficiency of a single $p-n$ junction solar cell can be calculated by Shockley Queisser limits. With the proposed theoretical approach, if we simulate the efficiency of pure silicon, that is, at a mole fraction " 0 ," the efficiency is less as compared to $\mathrm{SiGe}$ alloy, as shown in Table 2. This is because at higher band gap most of the solar photons are not able to convert into electrons that flow through the circuit [14]. Therefore, to reduce band gap and to enhance absorption, alloy of silicon and germanium is constructed. In Table 3, some present methods are compared with the proposed method.

\section{Conclusion}

This user interface can be used for speculative analysis of silicon germanium heterostructure solar cell. Here, modelling of different layer is done easily and it instantly switches 
over to the calculation mode. If needed, arbitrary parameter variation could be done for simulation of different characteristics. This is very useful in deciding the perfect combination of germanium content and thickness of silicon germanium layer as per the requirement. SiGe alloy layer is a tunable absorber layer, suitable for construction of efficient and optimized solar cell. According to [9], time for extraction of data was long, but, for this user interface, the result computation time is less. This GUI can be used to optimize the following $\mathrm{Si}_{1-x} \mathrm{Ge}_{x}$ parameters: (a) properties variation with variable layer thickness; (b) effect on electrical and structural properties under variation of temperature. In future, the program can be enhanced for the simulation of different heterojunction solar cell. An efficiency of $17.73 \%$ was realized with the proposed technique and this heterojunction method will overcome the maximum practical Si efficiency of $26 \%$ in the future.

\section{Conflict of Interests}

The authors declare that there is no conflict of interests regarding the publication of this paper.

\section{Acknowledgments}

The authors wish to acknowledge Dr. Mukul Kumar Das, Associate Professor in Department of Electronics Engineering, Indian School of Mines (ISM), Dhanbad, and Mr. Santosh Kumar Choudhary, Ph.D. Scholar at the Department of Electronics Engineering, ISM, Dhanbad, for their guidance.

\section{References}

[1] G. Sun, F. Chang, and R. A. Soref, "High efficiency thin-film crystalline Si/Ge tandem solar cell," Optics Express, vol. 18, no. 4, pp. 3746-3753, 2010.

[2] S. T. Chang, M. H. Liao, and W.-K. Lin, "Si/SiGe hetero-junction solar cell with optimization design and theoretical analysis," Thin Solid Films, vol. 519, no. 15, pp. 5022-5025, 2011.

[3] R. R. King, D. C. Law, K. M. Edmondson et al., “ $40 \%$ efficient metamorphic GaInP/GaInAs/Ge multijunction solar cells," Applied Physics Letters, vol. 90, Article ID 183516, 2007.

[4] K. Said, J. Poortmans, M. Caymax et al., "Design, fabrication, and analysis of crystalline Si-SiGe heterostructure thinfilm solar cells," IEEE Transactions on Electron Devices, vol. 46, no. 10, pp. 2103-2110, 1999.

[5] T. Matsui, C.-W. Chang, T. Takada, M. Isomura, H. Fujiwara, and M. Kondo, "Microcrystalline $\mathrm{Si}_{1-x} \mathrm{Ge}_{x}$ solar cells exhibiting enhanced infrared response with reduced absorber thickness," Applied Physics Express, vol. 1, no. 3, Article ID 031501, 2008.

[6] S. S. Hegedus, "Current-voltage analysis of a-Si and a-SiGe solar cells including voltage-dependent photocurrent collection," Progress in Photovoltaics: Research and Applications, vol. 5, no. 3, pp. 151-168, 1997.

[7] M. A. Wistey, Y.-Y. Fang, J. Tolle, A. V. G. Chizmeshya, and J. Kouvetakis, "Chemical routes to $\mathrm{Ge} / \mathrm{Si}(100)$ structures for low temperature Si-based semiconductor applications," Applied Physics Letters, vol. 90, no. 8, Article ID 082108, 2007.

[8] K. Said, J. Poortmans, M. Caymax et al., "Design, fabrication, and analysis of crystalline Si-SiGe heterostructure thin-film solar cells," IEEE Transactions on Electron Devices, vol. 46, no. 10, pp. 2103-2110, 1999.

[9] A. K. Singh, J. Tiwari, A. Yadav, and R. K. Jha, "Analysis of $\mathrm{Si} / \mathrm{SiGe}$ heterostructure solar cell," Journal of Energy, vol. 2014, Article ID 946406, 7 pages, 2014.

[10] http://www.pveducation.org.

[11] S. Chatterjee, S. Singh, and H. Pal, "Effect of multijunction approach on electrical measurements of silicon and germanium alloy based thin-film solar cell using AMPS-1D," International Journal of Photoenergy, vol. 2014, Article ID 653206, 6 pages, 2014.

[12] S. M. Sze, Physics of Semiconductor Device, John Wiley \& Sons, New York, NY, USA, 1969.

[13] http://www.siliconfareast.com/sigegaas.htm.

[14] W. Shockley and H. J. Queisser, "Detailed balance limit of efficiency of p-n junction solar cells," Journal of Applied Physics, vol. 32, no. 3, pp. 510-519, 1961. 

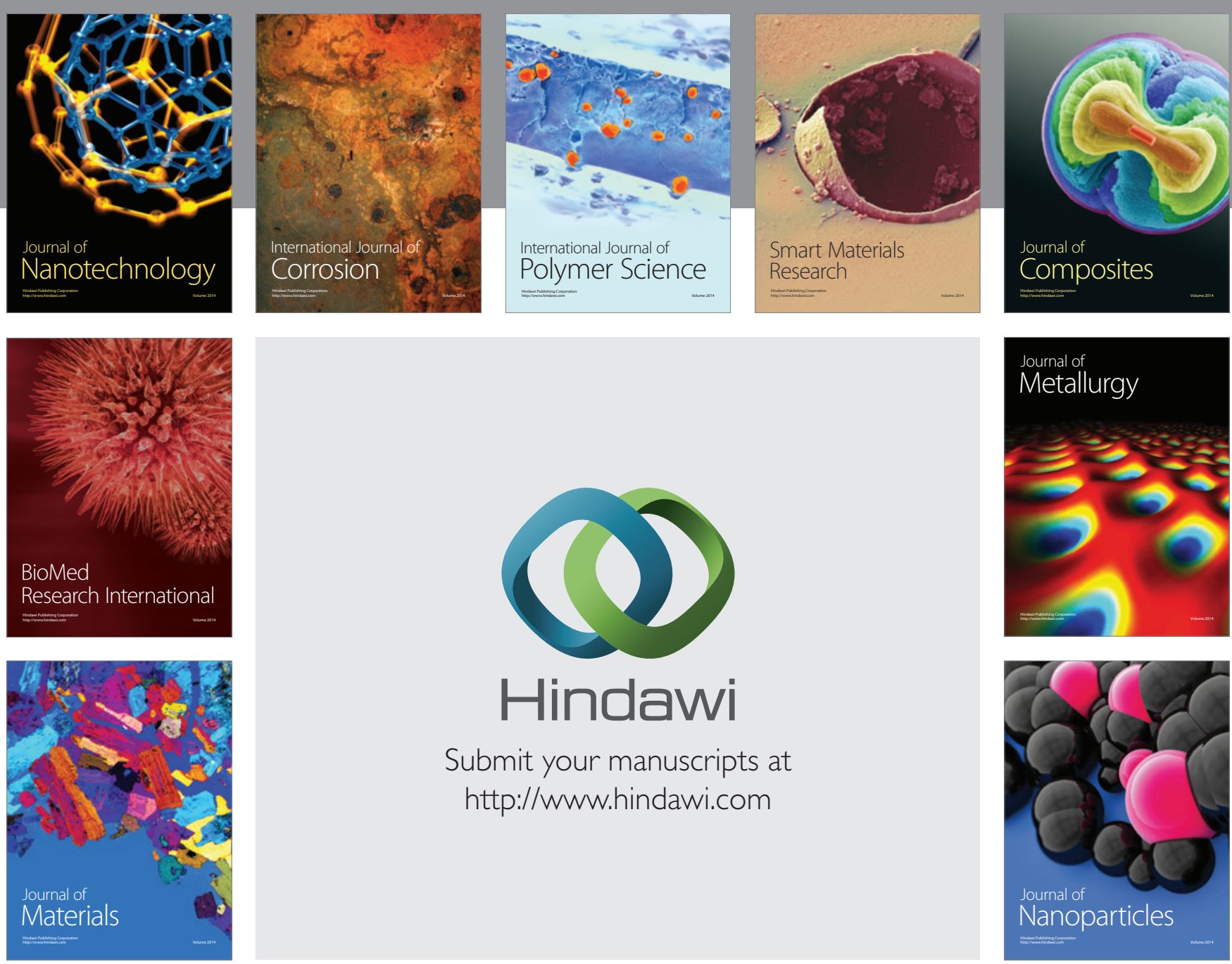

Submit your manuscripts at http://www.hindawi.com
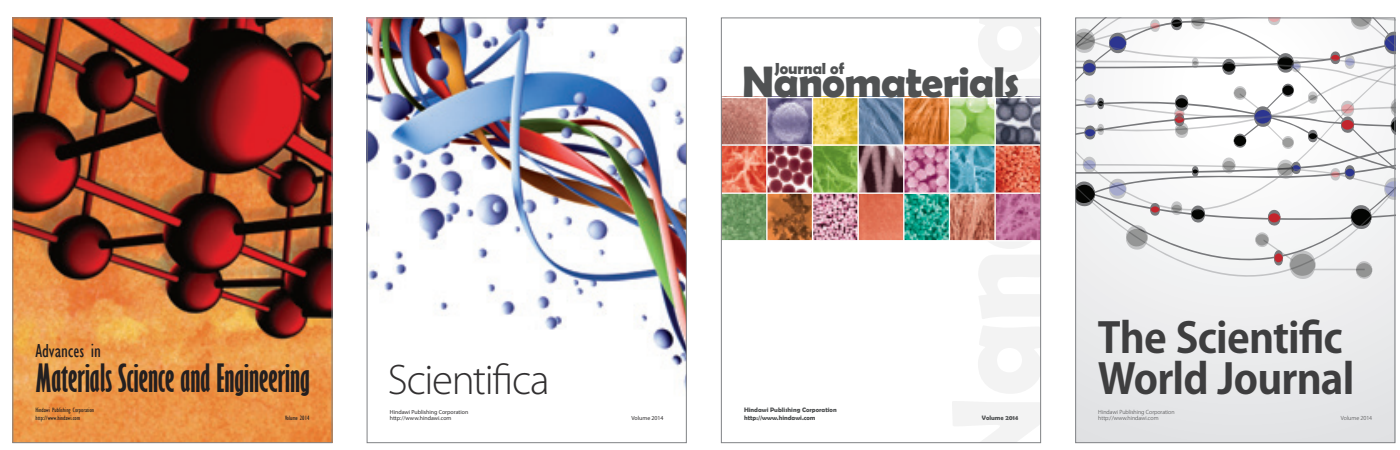

\section{The Scientific World Journal}
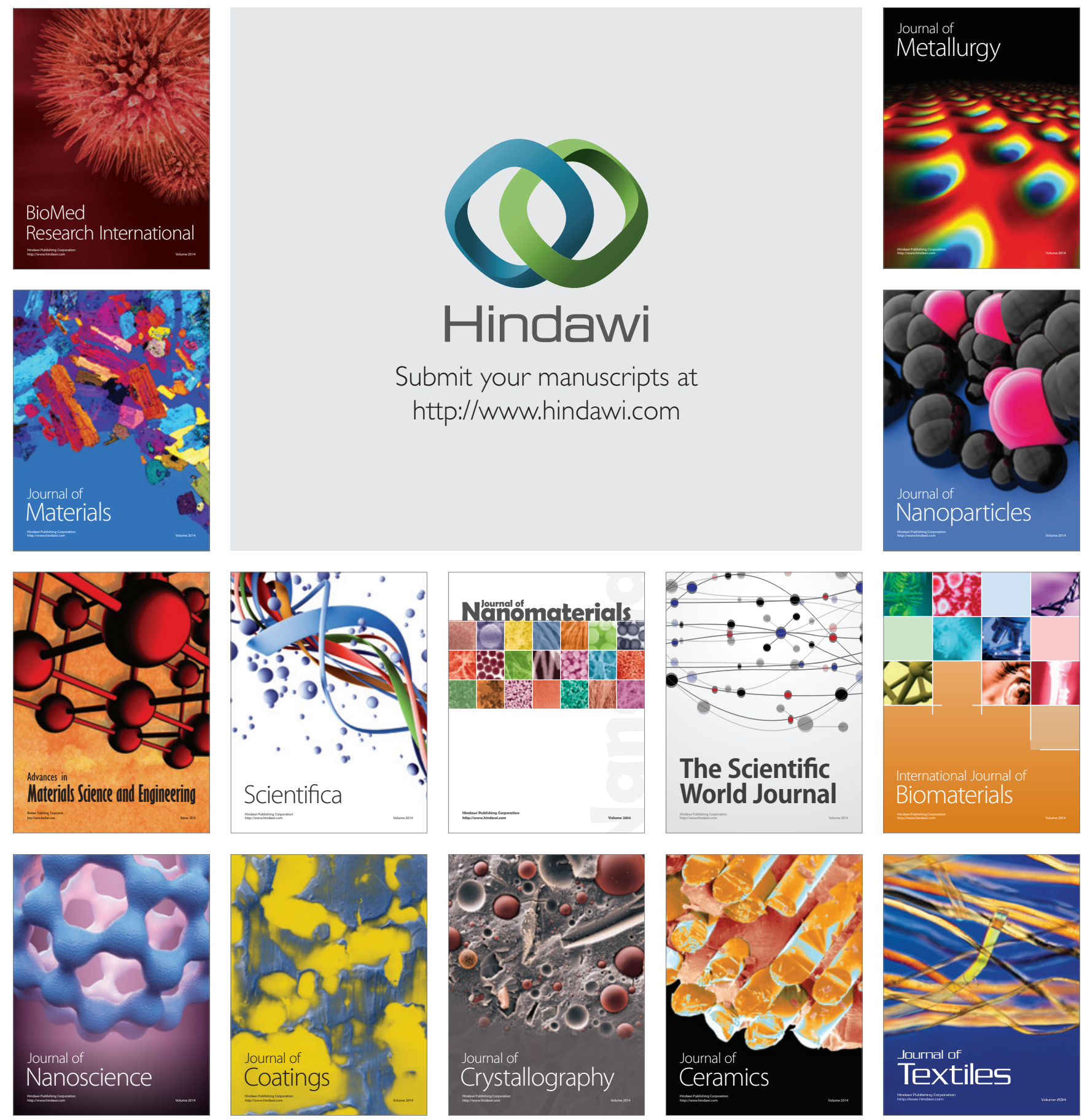